\title{
Prevalence of eye diseases in primary school children in a rural area of Tanzania
}

\author{
Susanne H Wedner, David A Ross, Rebecca Balira, Lucas Kaji, Allen Foster
}

\begin{abstract}
Aims-The study measured the prevalence of eye diseases in primary school children between 7 and 19 years of age in a rural area of Tanzania, and investigated whether teachers could successfully provide the first component of a school eye screening service.

Methods-Teachers from each of three primary schools in Mwanza Region tested visual acuity using a Snellen's E chart in 1438 pupils. 1386 of these pupils were then interviewed and underwent a full eye examination by an eye team.

Results-10 pupils $(0.7 \%)$ had bilateral poor eyesight (visual acuity worse than $6 / 12)$, and an additional 14 pupils (1.0\%) had unilateral poor eyesight. Significant refractive errors causing visual acuity less than $6 / 12(1.0 \%)$, strabismus $(0.5 \%)$, and amblyopia $(0.2 \%)$ were uncommon. Overall, 76 pupils $(5.5 \%)$ had active trachoma, though the prevalence was $15.5 \%$ in the poorest school. 73 pupils $(5.3 \%)$ reported night blindness, eight $(0.6 \%)$ had Bitot's spots, and $11(0.8 \%)$ had corneal scars. Simple screening by teachers correctly identified $80 \%$ of the pupils who were found to have bilateral poor eyesight by the eye team, with $91 \%$ specificity.

Conclusion-The prevalence of significant refractive errors was not high enough to justify a school eye screening programme solely for this purpose. However, a programme may be justified in areas where trachoma is common. Further research is needed to validate the frequent reports of night blindness and to establish the public health importance of vitamin A deficiency in this age group.
\end{abstract}

(Br f Ophthalmol 2000;84:1291-1297)

In developed countries, screening for eye diseases in preschool/school children is done routinely even though there is active debate about its value and cost effectiveness. ${ }^{12}$ Screening is mainly directed towards identifying children with amblyopia, strabismus, and refractive errors. ${ }^{3-6}$ As in most African countries, no national preschool or school eye screening service exists in Tanzania and screening is only performed sporadically by some local eye personnel. The great majority of children never have an eye examination.

Very few data are available on the prevalence of eye diseases in primary school children in sub-Saharan Africa. In 1972, Yassur and colleagues examined 1550 school children in Rwanda aged between 10 and 18 years for amblyopia and found a prevalence of $1.2 \%$ with visual acuity worse than $6 / 9$ (VA <6/9). Population based surveys into the causes of impaired visual acuity often do not report the age distributions of their study samples ${ }^{89}$ and frequently deliberately exclude refractive errors. ${ }^{10-12}$ Of greatest importance to a school screening programme in sub-Saharan Africa would be the prevalence of refractive errors leading to impaired visual acuity that could be corrected with glasses, and the prevalence of preventable diseases such as trachoma and vitamin A deficiency. Even though blinding xerophthalmia is mainly a problem of the under 6 year age group, night blindness is sometimes commoner in children who are older than this. ${ }^{12}{ }^{13}$ Though not severely disabling, it is a nuisance and could interfere with homework.

"Aide et Action", a French nongovernmental organisation, started work in the Mwanza Region of Tanzania in 1996. The organisation's main aim is to create an environment that encourages quality education by supporting the primary education sector in the region. This is done through activities to improve teachers' motivation and training and by mobilising community support for the schools. Limited infrastructural support is also provided. The organisation is considering the inclusion of health activities within its local programme. A primary school survey was carried out as part of the preparations for this.

The objectives of this survey were:

(1) To establish whether there was enough preventable and treatable eye disease in primary school children to justify the implementation of a school screening programme for eye diseases.

(2) To establish whether teachers could successfully provide the first component of an eye screening programme by testing visual acuity using Snellen's E test chart and administering a few simple questions about eyesight.

\section{Methods}

PARTICIPANT SELECTION

The survey took place between early September and early November 1998 in Magu District, Tanzania, a rural district of Mwanza Region at the southern shore of Lake Victoria.

All pupils $(n=1481)$ who were registered as attending three rural government primary schools supported by Aide et Action (Sagani, Nyashimo, and Mwamayombo) were eligible for the study. Screening for eye diseases had not been offered in these schools before. Research and ethics clearance was obtained from the government of Tanzania through its medical research coordinating committee, and 
from the ethics committee of the London School of Hygiene and Tropical Medicine. Consent for the study was also obtained from the relevant regional and district authorities and from the three school committees and parents. Although the parents were offered the option of withdrawing their child from the study, no child was withdrawn.

\section{TEACHERS' EYE SCREENING}

Two specially chosen teachers per school were trained in a one day workshop to assess pupils' visual acuity and in how to administer a short questionnaire to them. They were taught how to grade the pupils' eyesight for each eye separately by whether or not the pupil could see at least three out of five optotypes of the $6 / 12$ line of Snellen's E chart at 6 metres. The questionnaire consisted of three questions:

(1) Can you see what has been written on the blackboard well?

(2) Can you see what has been written in your book well?

(3) Have you got any other problems with your eyes?

The workshop was held in the local language (Swahili) by an ophthalmic nursing officer (ONO) and supervised by an ophthalmologist (SW). It included theoretical training in how to administer the questionnaire and how to test visual acuity in children with practical demonstrations by the instructors, including demonstrations of common errors (for example, testing without checking beforehand that the child had understood the instructions, incomplete covering of the eye that was not being tested, etc). This was followed by practical sessions where the teachers practised on each other until they were fully competent. The practical session included testing people who had been made artificially short sighted with spectacles to give the teachers experience of testing people with poor eyesight as well as those with normal eyesight. One pair of teachers performed the test and the other pair watched and then commented. The teachers then went on to administer the questionnaire and to test VA on primary school children of different age groups under supervision. Written guidelines summarising the testing conditions and procedures and common pitfalls were distributed to all of the teachers and discussed again at the

Table 1 Prevalence of eye diseases in the 1386 study children examined

\begin{tabular}{|c|c|c|c|}
\hline \multirow[b]{2}{*}{ Eye disease } & \multicolumn{2}{|c|}{ Prevalence } & \multirow{2}{*}{$\begin{array}{l}95 \% \text { Confidence } \\
\text { intervals }(\%)\end{array}$} \\
\hline & No & $\%$ & \\
\hline Refractive errors $(\mathrm{VA}<6 / 12)$ (unilateral 5, bilateral 9) & 14 & 1.01 & $0.48-1.54$ \\
\hline Strabismus & 7 & 0.51 & $0.13-0.88$ \\
\hline Amblyopia & 3 & 0.22 & $0.00-0.46$ \\
\hline Trachoma $^{\star}$ (TF, TI 76); (TS 1) & 77 & 5.56 & $4.35-6.77$ \\
\hline Night blindness & 73 & 5.27 & $4.09-6.45$ \\
\hline Bitot's spots & 8 & 0.58 & $0.18-0.98$ \\
\hline Corneal scar (unilateral 9, bilateral 2) & 11 & 0.79 & $0.32-1.26$ \\
\hline Vernal keratoconjunctivitis & 5 & 0.36 & $0.04-0.68$ \\
\hline Cataract (unilateral 2, bilateral 1) & 3 & 0.22 & $0.00-0.47$ \\
\hline Macular disease (macular scar 3, maculopathy 1 ) & 4 & 0.29 & $0.01-0.57$ \\
\hline Otherst & 20 & 1.44 & $0.81-2.07$ \\
\hline
\end{tabular}

${ }^{\star}$ Using the simplified WHO grading system ${ }^{14}: \mathrm{TF}=$ trachoma inflammation-follicular; $\mathrm{TI}=$ trachoma inflammation-intense; $\mathrm{TS}=$ trachomatous scarring.

†Others: hordeolum (5), subconjunctival haemorrhage (3), acute conjunctivitis (7), pterygium

(1), corneal ulcer (1), iris coloboma (1), suspected glaucoma (1), post evisceration (1). end of the workshop. The teachers then returned to their schools with Snellen's E charts and were given 1 week to administer the questionnaire and to test the eyesight of all their pupils. They were instructed not to delegate this task to other untrained teachers.

EYE EXAMINATION BY EYE TEAM

After completion of the teachers' eye screening, an eye team consisting of an ophthalmologist (SW), an ophthalmic nursing officer, and four interviewers (secondary school leavers) visited all three schools. During a 3-5 day period in each school, they examined all the pupils who were present.

The interviewers had been trained in the application of a questionnaire and how to test visual acuity (VA) using Snellen's E chart. The questionnaire provided information of the pupils' socioeconomic status, their eyesight for distance and near and their ability to see well in low levels of light (for example, in the evening or at night when using a torch or a spirit lamp). In a $10 \%$ randomly chosen sample, the questionnaire was reapplied and the VA retested by a different interviewer without knowledge of the original results. Computer generated random numbers were preselected to choose one pupil out of each sequential group of 10 . These numbers were held by the ophthalmologist, so that the interviewers were not aware which pupils would be rechecked. Any discrepancies in questionnaire results or VA tests were clarified by the ophthalmologist. Visual acuity was also retested in all pupils with $\mathrm{VA}=6 / 12$ on the first examination. In addition, the ophthalmologist retested the VA of all pupils in whom there were discrepant results between the teachers' VA testing and that of the interviewer.

The ophthalmic nursing officer then examined the eyes of all pupils with a torch and a direct ophthalmoscope. The examination was terminated there for all pupils with bilateral VAL $\geqslant 6 / 12$ and normal eyes on examination, whereas all 157 pupils with poor eyesight in at least one eye and/or an abnormality found on eye examination (as listed in Table 1) were sent to the ophthalmologist for further examination. Night blindness reports were not used as a referral criterion, since its validity in this population is uncertain (see discussion). In addition, 130 randomly chosen pupils were also examined by the ophthalmologist with a torch and indirect ophthalmoscope to provide an assessment of the ophthalmic nursing officer's performance. Random selection procedures were the same as for the interviewers.

The ophthalmologist performed a full eye examination in all the 157 referred pupils. This included screening for strabismus (motility check, Hirschberg, and cover tests), examination of the anterior segment with a portable slit lamp and examination of the posterior pole in miosis with a direct ophthalmoscope. Schiøtz tonometry, indirect ophthalmoscopy in mydriasis, and retinoscopy were performed where indicated (for example, for suspected glaucoma, retinal disease, and if subjective refraction was not possible in a pupil). Stages of tra- 
choma and vitamin A deficiency were classified using WHO definitions. ${ }^{14}{ }^{15}$ Treatment and further referrals were initiated as appropriate.

DATA PROCESSING AND ANALYSIS

Data processing and analysis were done in the National Institute for Medical Research (NIMR) in Mwanza. After manual checking of forms by the ophthalmologist, all data were independently entered onto computers using DBASE 4 (Borland) software by two different data entry clerks, and the resulting data sets compared to minimise data entry errors. Range and consistency checks were done on all variables. Statistical tests of significance were conducted using $\chi^{2}$ tests for proportions or for trend as appropriate. Two tailed tests were always used. Univariate analyses and multivariate logistic regression adjusting for age, sex, and other significant variables were performed using STATA 6.0 (Stata Corp).

\section{Results}

PREVALENCE OF EYE DISEASES

A total of 1386 (94\%) of the study children between the ages of 7 and 19 years were examined by the eye team; 141 pupils $(10.2 \%)$ were found to have abnormalities or poor eyesight $(\mathrm{VA}<6 / 12)$ in at least one eye. An additional 73 $(5.3 \%)$ pupils reported having night blindness (Table 1).

Bilateral poor eyesight $(\mathrm{VA}<6 / 12$ in the better eye) was found in 10 pupils and unilateral poor eyesight $(\mathrm{VA}<6 / 12$ in either eye) in an additional 14 pupils (Table 2). None had bilateral blindness (VA $<3 / 60$ in the better eye), but one child had visual acuity of 3/24 in the better eye (severe visual impairment), and five of the 24 pupils with poor eyesight $(5 / 1386=0.36 \%)$ were blind in one eye $(\mathrm{VA}<3 / 60)$. The causes of unilateral blindness were cataract (two), macular scars (two), and evisceration (one). Significant refractive errors causing visual acuity less than 6/12, strabismus and amblyopia were uncommon; each had a prevalence of $1 \%$ or less (Table 1). All the 14 pupils with refractive errors were myopic. Refractive errors were responsible for nine of the 10 cases of poor bilateral eyesight $(\mathrm{VA}<6 / 12$ in both eyes) (Table 2). In all 10 pupils with bilateral poor eyesight, visual acuity was improved to normal $(\mathrm{VA} \geqslant 6 / 12)$ in at least one eye by either providing glasses for refractive errors (nine pupils) or by operating on the one pupil with bilateral cataracts. Refractive errors $(n=5 ; 0.36 \%)$ and macular disease $(n=4 ; 0.29 \%)$ were the commonest problems in the 14 additional pupils with unilateral visual impairment (VA $<6 / 12$ in one eye) (Table 2).

Seventy six children $(5.5 \%)$ were diagnosed as having active trachoma (follicular trachoma with or without inflammation). In addition, one child had trachomatous scarring (Table 1). Half of the children with trachoma (38/77) came from one school (Sagani) (Table 3; prevalence by school $\mathrm{p}<0.001)$, which is in a poorer area with less access to water than the other two schools. The majority of pupils with trachoma $(63 / 77=82 \%)$ were attending school year 1 to 3 (Table $3 ; \chi^{2}$ test for heterogeneity
Table 2 Causes of impaired visual acuity in study children

\begin{tabular}{lll}
\hline & \multicolumn{2}{c}{ Poor eyesight $(V A<6 / 12)$} \\
\cline { 2 - 3 } Cause & Bilateral & Unilateral \\
\hline Significant refractive error & $9^{\star}$ & 5 \\
Cataract & 1 & 1 \\
Corneal scar & 0 & 1 \\
Macular disease & 0 & 4 \\
Strabismic amblyopia & 0 & 2 \\
Post evisceration & 0 & 1 \\
Total & 10 & 14 \\
\hline
\end{tabular}

*Anisometropic amblyopia in one case.

Table 3 Prevalence of trachoma by school and by school year

\begin{tabular}{lccc}
\hline Distribution & $\begin{array}{l}\text { Trachoma } \\
(\%)\end{array}$ & No & p Value \\
\hline School & 15.5 & 245 & \\
$\quad$ Sagani & 3.8 & 708 & $<0.001$ \\
$\quad$ Nyashimo & 2.8 & 433 & \\
$\quad$ Mwamayombo & 10.3 & 254 & \\
School year 1 & 6.8 & 235 & \\
School year 2 & 6.6 & 317 & \\
School year 3 & 3.2 & 251 & 0.001 \\
School year 4 & 2.0 & 98 & \\
School year 5 & 2.0 & 153 & \\
School year 6 & 1.3 & 78 & \\
School year 7 & & & \\
\hline
\end{tabular}

$\mathrm{p}=0.001$ ), which was paralleled by $85 \%$ of the children with trachoma being less than 13 years old (Table 4). There was no difference in the prevalence of trachoma between boys and girls $(p=0.8$; Table 4). Children with trachoma usually came from poorer households (Table 4). For example, they were less likely to have a father in salaried employment $(p=0.015)$ or to have literate parents $(\mathrm{p}=0.004)$, and the households they lived in less commonly owned a bicycle $(p=0.016)$ or a radio $(p<0.001)$. Children with trachoma were less likely to live in houses built with cement as opposed to mud blocks $(p=0.002)$ or in houses roofed with iron sheets as opposed to thatch $(p=0.010)$. All these differences were still significant after adjusting for age and sex. After adjusting for age, sex, and the other significant variables, children with trachoma were still less likely to come from a household that owned a radio or to live in a house built from cement blocks. Their household was more likely to own more than 10 cows. Death of the child's mother was of borderline significance for a higher prevalence of trachoma ( $\mathrm{p}=0.05 ; 95 \%$ CI $1.01-$ 13.76) (Table 4).

A relatively high proportion (5.3\%) of pupils reported night blindness (inability to see well in low levels of light), and Bitot's spots were found in $0.6 \%$ of pupils (Table 1 ). However, none of the pupils who reported night blindness had Bitot's spots. As for trachoma, night blindness reports were commoner in Sagani school $(11.0 \%)$ than in either of the other schools $(3.5 \%$ and $4.1 \%$ respectively) $(\mathrm{p}<0.001)$. The prevalence of Bitot's spots was similar and always less than $1.0 \%$ in each of the three schools $(\mathrm{p}=0.381)$. Although corneal scars were found in 11 children $(0.8 \%)$ ) (Table 1 ), only one pupil had unilateral impaired eyesight $(V A=6 / 18)$ due to a corneal scar (Table 2 ), and bilateral corneal scars were rare (two pupils). 
Table 4 Potential risk factors for trachoma

\begin{tabular}{|c|c|c|c|c|c|c|c|c|}
\hline \multirow{2}{*}{$\begin{array}{l}\text { Characteristics } \\
\text { Male }\end{array}$} & \multirow{2}{*}{$\frac{N o^{\star}}{646}$} & \multirow{2}{*}{$\frac{\text { Trachoma (\%) }}{5.5}$} & \multirow{2}{*}{$\begin{array}{l}\text { Prevalence ratio } \\
1.0\end{array}$} & \multirow[t]{2}{*}{$p$ Value } & \multicolumn{2}{|c|}{$O R \ddagger(95 \% C I)$} & \multicolumn{2}{|c|}{$O R \int(95 \% C I)$} \\
\hline & & & & & 1.0 & $\mathrm{p}=0.8$ & 1.0 & $\mathrm{p}=0.7$ \\
\hline Female & 660 & 5.7 & 1.04 & 0.8 & 0.93 & $(0.58-1.49)$ & 0.92 & $(0.57-1.48)$ \\
\hline \multicolumn{9}{|l|}{ Age group } \\
\hline $7-8$ years & 178 & 15.7 & 1.0 & & 1.0 & $\mathrm{p}<0.001$ & 1.0 & $\mathrm{p}<0.001$ \\
\hline $9-10$ years & 325 & 5.2 & 0.3 & 0.001 & 0.29 & $(0.16-0.56)$ & 0.31 & $(0.16-0.60)$ \\
\hline $11-12$ years & 337 & 6.2 & 0.4 & 0.001 & 0.35 & $(0.19-0.64)$ & 0.35 & $(0.19-0.64)$ \\
\hline $13-14$ years & 300 & 2.7 & 0.2 & 0.001 & 0.15 & $(0.07-0.32)$ & 0.15 & $(0.07-0.35)$ \\
\hline $15+$ years & 242 & 1.2 & 0.08 & 0.001 & 0.07 & $(0.02-0.22)$ & 0.07 & $(0.02-0.24)$ \\
\hline Mother in salaried employment $\dagger$ & 53 & 1.9 & 1.0 & & 1.0 & $\mathrm{p}=0.6$ & 1.0 & $\mathrm{p}=0.6$ \\
\hline Mother not in salaried employment $\dagger$ & 1309 & 5.6 & 3.0 & 0.376 & 3.44 & $(0.46-25.8)$ & 1.73 & $(0.21-14.27)$ \\
\hline Mother alive & 1362 & 5.4 & 1.0 & & 1.0 & $\mathrm{p}=0.07$ & 1.0 & $\mathrm{p}=0.05$ \\
\hline Mother dead & 22 & 13.6 & 2.5 & 0.217 & 3.23 & $(0.89-11.74)$ & 3.74 & $(1.01-13.76)$ \\
\hline Father in salaried employment† & 152 & 1.3 & 1.0 & & 1.0 & $\mathrm{p}=0.03$ & 1.0 & $\mathrm{p}=0.15$ \\
\hline Father not in salaried employment $\dagger$ & 1152 & 6.2 & 4.8 & 0.015 & 5.04 & $(1.21-20.98)$ & 2.76 & $(0.65-11.73)$ \\
\hline Father alive & 1304 & 5.6 & 1.0 & & 1.0 & $\mathrm{p}=0.6$ & 1.0 & $\mathrm{p}=0.4$ \\
\hline Father dead & 67 & 4.5 & 0.8 & 0.867 & 0.75 & $(0.23-2.52)$ & 0.61 & $(0.18-2.10)$ \\
\hline Both parents reported literate & 934 & 4.1 & 1.0 & & 1.0 & $\mathrm{p}=0.004$ & 1.0 & $\mathrm{p}=0.13$ \\
\hline One parent reported literate & 339 & 8.8 & 2.2 & 0.002 & 2.7 & $(1.31-3.62)$ & 1.68 & $(0.99-2.88)$ \\
\hline Neither parent reported literate & 111 & 8.3 & 2.0 & 0.004 & 2.8 & $(1.14-5.38)$ & 1.63 & $(0.72-3.69)$ \\
\hline Household with bicycle & 1011 & 4.6 & 1.0 & & 1.0 & $\mathrm{p}=0.04$ & 1.0 & $\mathrm{p}=0.2$ \\
\hline Household without bicycle & 375 & 8.0 & 1.7 & 0.016 & 1.67 & $(1.03-2.71)$ & 1.48 & $(0.86-2.56)$ \\
\hline Household with car & 42 & 0.0 & 1.0 & & & & & \\
\hline Household without car & 1344 & 5.7 & $\infty$ & 0.110 & \multicolumn{2}{|c|}{ Cannot be estimated } & \multicolumn{2}{|c|}{ Cannot be estimated } \\
\hline Household with radio & 925 & 3.7 & 1.0 & & 1.0 & $\mathrm{p}<0.001$ & 1.0 & $\mathrm{p}=0.01$ \\
\hline Household without radio & 461 & 9.3 & 2.5 & $<0.001$ & 2.56 & $(1.59-4.11)$ & 2.51 & $(1.52-4.14)$ \\
\hline Household with 10 or more cows & 399 & 6.8 & 1.0 & & 1.0 & $\mathrm{p}=0.18$ & 1.0 & $\mathrm{p}=0.015$ \\
\hline Household with less than 10 cows & 986 & 5.1 & 0.8 & 0.212 & 0.71 & $(0.44-1.17)$ & 0.54 & $(0.32-0.91)$ \\
\hline House built from cement blocks & 231 & 1.3 & 1.0 & & 1.0 & $\mathrm{p}=0.007$ & 1.0 & $\mathrm{p}=0.023$ \\
\hline House built from mud & 1155 & 6.4 & 4.9 & 0.002 & 5.07 & $(1.57-16.34)$ & 4.00 & $(1.22-13.12)$ \\
\hline House roofed with iron sheets & 825 & 4.2 & 1.0 & & 1.0 & $\mathrm{p}=0.02$ & 1.0 & $\mathrm{p}=0.05$ \\
\hline House roofed with grass thatch & 561 & 7.5 & 1.8 & 0.010 & 1.77 & $(1.10-2.83)$ & 1.11 & $(0.65-1.90)$ \\
\hline
\end{tabular}

${ }^{\star}$ Between 1 and 15 children were not able to answer each of the questions.

†Not answered if parent had died.

$\ddagger$ Odds ratio adjusted for age and sex only.

$\$$ Multivariate odds ratio adjusted for age, sex, mother alive or dead, presence of radio, house building materials, and number of cows.

Two of the three pupils who had cataracts had visual deficit as a result (Table 2); one pupil had bilateral $\mathrm{VA}<6 / 12$, and one unilateral VA $<6 / 12$. One girl was referred for further examination because of suspected glaucoma. Only five pupils $(0.4 \%)$ were found to suffer from vernal keratoconjunctivitis (Table 1).

EVALUATION OF THE VALIDITY OF THE TEACHERS' EYE SCREENING

The teachers screened the eyesight of 1438 pupils; 1242 before the eye team's visit and another 196 pupils during the team's visit. The eye team rechecked visual acuity in 1386 of these children $(96.4 \%)$.

If the results of the teachers' VA test and their question about the child's distance eyesight are combined, and if all pupils whom the teacher reported as having either unilateral or bilateral $\mathrm{VA}<6 / 12$ are included, the screening by the teachers identified the great majority of pupils with bilateral poor eyesight (sensitivity: $80 \%$, specificity: $91 \%$ ). Using the VA test on its own, the sensitivity decreased to $70 \%$ (Table 5).

\section{DATA QUALITY}

In all, 168 pupils were randomly chosen for re-interview and repeat VA testing by a different VA tester. The extent of discrepancies between the two interviewers varied considerably from question to question, from $1 / 168$ $(0.6 \%$; language spoken by parents/guardians) to $26 / 168$ ( $15.5 \%$; exact number of siblings). However, out of the 14 questions in the sociodemographic part of the questionnaire, a discrepancy of $10.0 \%$ or more was only found in one question (exact number of siblings). The interinterviewer discrepancies for the questions assessing subjective quality of eyesight (near/distance/in low levels of light) were all present in less than $5.0 \%$.

When the ophthalmologist (SW) rechecked discrepant results with the pupils concerned, the answers sometimes agreed with those of one interviewer and sometimes with the other interviewer and, rarely, were changed again.

A discrepancy for visual acuity tests was defined as:

Table 5 Evaluation of teachers' eye screening results and of the ophthalmic nursing officer's (ONO) performance

\begin{tabular}{|c|c|c|c|c|c|}
\hline & True prevalence & Sensitivityt (\%) & Specificity $\neq(\%)$ & $P P V(\%) S$ & $N P V(\%) \emptyset$ \\
\hline Teachers' uni/bilateral VA $<6 / 12 v$ bilateral VA $<6 / 12$ by eye team & 0.72 & 70.0 & 97.0 & 14.9 & 99.8 \\
\hline $\begin{array}{l}\text { Teachers' uni/bilateral VA }<6 / 12 \text { or poor distance eyesight reported to } \\
\text { teachers } v \text { bilateral VA }<6 / 12 \text { by eye team }\end{array}$ & 0.72 & 80.0 & 91.4 & 6.5 & 99.8 \\
\hline Eye abnormality reported by ONO $v$ ophthalmologist’s results` & 10.0 & 92.3 & 100.0 & 100.0 & 99.2 \\
\hline
\end{tabular}

^Based on 130 of the pupils examined by the ONO who were also examined by the ophthalmologist, who was unaware of the ONO's results.

tSensitivity: the proportion of children defined as having the condition by the reference test (eg, eye abnormality reported by the ophthalmologist) who were also defined as having the condition by the screening test (eg, eye abnormality reported by the ONO)

$\ddagger$ Specificity: the proportion of children defined as not having the condition by the reference test (eg, no eye abnormality reported by the ophthalmologist) who were also defined as not having the condition by the screening test (eg, no eye abnormality reported by the ONO).

$§ P P V$ (positive predictive value): the proportion of children defined as having the condition by the screening test (eg, eye abnormality reported by the ONO) who were also defined as having the condition by the reference test (eg, eye abnormality reported by the ophthalmologist).

INPV (negative predictive value): the proportion of children defined as not having the condition by the screening test (eg, no eye abnormality reported by the ONO) who were also defined as not having the condition by the reference test (eg, no eye abnormality reported by the ophthalmologist). 
- any child having good eyesight in one test $(6 / 6,6 / 9,6 / 12)$ but poor eyesight $(<6 / 12)$ in the other test, or

- two lines or more difference when VA was tested by both testers as being less than $6 / 12$.

Using this definition there was only one discrepant result on the 168 repeat VA tests; one child with VA of 6/60 in one eye in the first test was reported to have $\mathrm{VA}=6 / 18$ in that eye in the repeat test.

A total of 130 children who had been examined by the ophthalmic nursing officer (ONO) were randomly chosen for re-examination by the ophthalmologist. Thirteen $(10.0 \%)$ of these children had eye abnormalities and 117 had normal eyes $(90.0 \%)$ diagnosed by the ophthalmologist. The ONO misdiagnosed only one child (who had trachoma) as having normal eyes (sensitivity: $12 / 13=92.3 \%$; specificity: $117 / 117=100 \%$ ) (Table 5).

Out of the 1386 pupils examined, the eye abnormalities (not including visual impairment) found by the ONO were confirmed by the ophthalmologist in $90 \%$ of the children (129/143).

\section{Discussion}

DATA QUALITY

Pupils were reliable respondents for most variables. However, some of the pupils were unreliable respondents for some of the questions about their sociodemographic background. This probably reflected genuine problems with the questions. Detailed investigation by the ophthalmologist did not reveal any clear tendency for one interviewer to have received the "correct" answer more often than the other interviewers. It also revealed conceptual difficulties with the one question that had the highest proportion of discrepancies (exact number of siblings). Children genuinely did not know who to count as their "brother" or "sister" in their culture where these terms are used very loosely. The extensive quality control did not reveal any evidence of fabrication of results by the interviewers or visual acuity testers.

Quality control by the ophthalmologist (SW) of the assessments made by the ONO revealed a very high level of agreement.

\section{REFRACTIVE ERRORS}

In our survey sample of 1386 rural primary school children, the prevalence of bilateral impaired visual acuity (VA<6/12 in the better eye) was relatively low at $0.7 \%$. Only four pupils $(0.3 \%)$ had $\mathrm{VA}<6 / 18$ in the better eye. Only one pupil had severe visual impairment (SVI), defined as VA $<6 / 60$ in the better eye, and no pupil was blind (VA $<3 / 60$ in the better eye). The school enrolment rate in Mwanza Region has been estimated between 53\% (net enrolment rate) and $72 \%$ (gross enrolment rate). ${ }^{16}$ The prevalence of significant refractive errors may have been higher (or lower) in children who were not attending school. However, these results in primary school children were similar to those found in a population based survey of 7043 children 5-14 years of age in
Botswana, ${ }^{17}$ where the prevalence of bilateral $\mathrm{VA}<6 / 18$ was $0.2 \%$.

In our study sample, refractive errors caused almost all of the cases of bilateral visual impairment (9/10), and a substantial proportion of those with unilateral impairment $(5 / 14)$ (Table 2). Only pupils with $\mathrm{VA}<6 / 12$ in either eye were refracted because the compliance with prescribed glasses was expected to be low in children with minor refractive errors. ${ }^{18}$ This may also explain the absence of hypermetropia, since only high degrees of hypermetropia lead to a decrease in visual acuity in children. In all our study children with refractive errors, visual acuity increased to within the normal range $(6 / 12$ or better) in at least one eye with glasses. Again these findings were similar to these from the study in Botswana where 15 of the 17 cases of bilateral poor eyesight were due to refractive errors and after correction all of these children had good eyesight, defined in that study as $\mathrm{VA} \geqslant 6 / 18 .{ }^{17}$

Although differences in definitions complicate comparisons, the prevalences of impaired visual acuity and of refractive errors found in these two African surveys were lower than those in surveys reported from non-African countries. ${ }^{5}$ 19-21 Bilateral visual impairment (VA<6/18) was found in 3.1\% and SVI $(\mathrm{VA}<6 /$ 60 ) in $0.5 \%$ of urban Indian schoolchildren. ${ }^{19}$ Similarly, the prevalence of refractive errors was high; using a definition of refractive errors of $\geqslant 0.5$ dioptres, the prevalence of myopia was $8.6 \%$, hyperopia $22.6 \%$, and astigmatism $10.3 \%{ }^{19}$ Ten per cent of 12853 ten year old children in the UK were found to wear glasses, but only $80 \%$ of the children who wore glasses had uncorrected VA of less than $6 / 9 .^{20}$ In a study of Chinese schoolchildren in two primary and two secondary schools, myopia of $\geqslant 0.5$ dioptres was detected in up to $50 \%$, and $24 \%$ had unaided visual acuity of $6 / 12$ or worse. $^{21}$

These differences may be due to racial/ ethnic variations in the prevalence of refractive errors, and/or due to different lifestyles or living conditions. The prevalence of myopia in African American children in an inner city school in the USA (preschool to second grade) was found to be as high as in children in a predominantly white community, whereas a national survey done 20 years earlier had found that the prevalence in African American pupils was almost half that observed in their white peers. ${ }^{5}$ This finding implies that differences in lifestyles (for example, reading, watching TV, or computer visual display units), living conditions (for example, nutrition) or medical care (for example, unnecessary or overcorrection of refractive errors which may worsen the refractive error by inhibiting natural "emmetropisation") may be more important than racial/ ethnic differences. ${ }^{2}$ Studies on children from families of high socioeconomic status in African cities might shed further light on this issue.

\section{TRACHOMA}

Trachoma was classified as being a problem of public health importance in only one of our 
study schools (Sagani) where the prevalence of active trachoma was $15.5 \%$ (Table 3 ). Sagani is the poorest of the three communities and is furthest from Lake Victoria. As expected from previous studies, ${ }^{22-24}$ active trachoma was commonest in young children attending the first three school years (Tables 3 and 4), in children from the poorest households, and in those coming from households with large numbers of cattle (Table 4). ${ }^{25}$ The prevalence of trachoma was similar in girls and in boys (Table 4).

\section{VITAMIN A DEFICIENCY}

Night blindness was reported by $5.3 \%$ of pupils in our study sample (Table 1 ).

However, further investigations are needed to confirm whether these reports were valid and the result of vitamin A deficiency, especially since no specific term seems to exist for night blindness in Sukuma, the main local language. However, the fact that eight pupils had Bitot's spots $(0.6 \%)$ indicates that xerophthalmia must be present either in this age group or in younger children. The frequency of lesions that are unresponsive to vitamin $\mathrm{A}$ and therefore not due to recent vitamin A deficiency increases in school age children. ${ }^{26}{ }^{27}$ This may explain why the pupils with Bitot's spots had no other evidence of xerophthalmia. In school age children the extent of active xerophthalmia and its clinical importance are poorly understood. Studies of the prevalence of xerophthalmia in school age children that have been conducted in areas where it was known to be present in younger children have reported prevalences of Bitot's spots ranging from $1.0 \%$ to $9.2 \%$ of children and night blindness prevalences ranging from $0.0 \%$ to $3.6 \% .^{13}{ }^{28-31}$ Further studies are planned in Mwanza Region of the validity of reported night blindness using a scotopic vision tester ${ }^{32}$ and on the prevalence of active xerophthalmia and subclinical vitamin A deficiency in this age group and in younger children.

TEACHERS' EYE SCREENING

Teachers have been used in India to screen visual acuity in schoolchildren. ${ }^{23}$ In our survey, selected teachers were trained to test visual acuity and then asked to screen all the pupils in their schools. However, some of the teachers delegated part of the screening to untrained colleagues. Also in one school about $40 \%$ of the children had not been screened before the arrival of the eye team, while in another school data were available for all the pupils, even the ones who had left the school long before the survey, so data must have been fabricated for these pupils. With strict supervision to make sure that only trained teachers do the screening and to try to eliminate fabricated data, the sensitivity for the teachers' screening (VA test and one question on distance eyesight) could well be higher than $80 \%$. Even VA testing on its own may then be a sensitive enough screening test. However, any screening by teachers or others will depend not only on the accuracy of the screening, but also on the prevalence and the public health importance of poor visual acuity in the population screened.
POLICY AND PROGRAMME IMPLICATIONS

Many factors need to be considered when deciding whether or not to introduce an eye screening programme in primary schools. These include the prevalence and health, educational, or work impact of poor eyesight within this population, the human and financial resources available for screening, the cost and effectiveness of the screening and the treatment given, and the availability and compliance with any treatment offered. No studies of the cost effectiveness of primary school screening for eye diseases have been reported from developing countries. Furthermore, there are no data on the impact of visual impairment, as opposed to blindness, on school or work performance in the context of rural African villages similar to the ones in this survey. Given this lack of objective data, any judgments related to whether or not to introduce a primary school eye screening programme are necessarily subjective. Several African countries have a policy that ophthalmic nurses should conduct regular eye screening in primary schools, though this policy is rarely acted on. In our opinion, the prevalence of significant refractive errors that caused bilateral visual impairment $(\mathrm{VA}<6 / 12$ in the better eye) was too low at $0.6 \%$ to be the sole justification for a screening programme. In one of the three schools, trachoma was common enough at $15.5 \%$ to justify regular screening and treatment. However, since the prevalence was much lower than this in the other two schools $(3.8 \%$ and $2.8 \%$, respectively), a further survey including a larger number of schools is required before a definite recommendation can be made as to whether trachoma is sufficiently prevalent to justify a large scale school eye screening programme in this area of Tanzania. As discussed above, further studies are needed to establish whether vitamin A deficiency is a problem of public health importance in primary school children in Mwanza Region. Even if this is so, this would not necessarily be a justification for routine eye screening, since the likely intervention would not be targeted at individual pupils but would be universal vitamin A supplementation to all pupils. In areas where a school screening programme is introduced, teachers could do the VA screening as long as they are well trained and supervised.

This study was supported by the Health and Population Division of the UK Department for International Development and by Aide et Action, Tanzania. The Department for International Development can accept no responsibility for any information provided or views expressed. The authors thank $\mathrm{Mr}$ Constantine Meleka, Dominique Wendling, and Jim Todd for their assistance.

1 Rahi JS, Dezateux C. The future of preschool vision screening services in Britain. BMF 1997;315:1247-8.

2 Wormald R. Screening in ophthalmology. In: Johnson GJ, diseases. London: Chapman and Hall Medical, 1998:83100.

3 Yang YF, Cole MD. Visual acuity testing in schools:what needs to be done. BMF 1996;313:1053

4 Simons K. Preschool vision screening: rationale, methodology and outcome. Surv Ophthalmol 1996;41:3-30.

5 Preslan MW, Novak A. Baltimore vision screening project. Ophthalmology 1996;103:105-9.

6 Ehrlich MI, Reinecke RD, Simons K. Preschool vision screening for amblyopia and strabismus. Programs, methods, guidelines, 1983. Surv Ophthalmol 1983;28:145-63. 
7 Yassur Y, Yassur S, Zaifrani S, et al. Amblyopia among Afri8 Tizazu T, Mburu FM. Prevalence and causes of vision loss in southern Sudan. Soc Sci Med 1983;17:1785-8.

Ayanru JO. Blindness in the midwestern state of Nigeria Ayanru JO. Blindness in the midwe
Trop Geogr Med 1983;26:325-32.

10 Rapoza PA, West SK, Katala SJ, et al. Prevalence and causes of vision loss in central Tanzania. Int Ophthalmol 1991;15: 123-9.

11 Chirambo MC, Tielsch JM, West KP, et al. Blindness and visual impairment in southern Malawi. Bull World Health Organ 1986;64:567-72.

12 Loewenthal R, Pe'er J. A prevalence survey of ophthalmic diseases among the Turkana tribe in north-west Kenya. $B r$ f Ophthalmol 1990;74:84-8.

13 Gopaldas T. Vitamin A deficiency beyond the preschool years. In: West KP, ed. Bellagio Meeting on vitamin $A$ deficiency and childhood mortality. New York: Helen Keller deficiency and childhood

14 Thylefors B, Dawson CR, Jones BR, et al. A simple system for the assessment of trachoma and its complications. Bull for the assessment of trachoma and its

15 World Health Organization. Control of vitamin A deficiency and xerophthalmia. 1982;672:1-70.

16 Ministry of Education and Culture, Tanzania. Basic statistics in education. 1999:1-48.

17 Gilbert CE. A pilot study to evaluate logistics and methods for a prevalence and causes survey of visual impairment and hearing impairment in children. Unpublished report to the Ministry of Health, Gaborone, Botswana 1995:1-34.

18 Kansara HT, D'Souza S. 5 years school eye screening-where are we now? Commun Eye Health 1996;9:3-4.

19 Kalikivayi V, Naduvilath T, Bansal A, et al. Visual impairment in school children in southern India. Indian $\mathcal{F}$ Ophthalmol 1997;45:129-34.

20 Stewart-Brown SL. Spectacle prescribing among 10-yearold children. Br f Ophthalmol 1985;69:874-80.
21 Chung KM, Mohidin N, Yeow PT, et al. Prevalence of visual disorders in Chinese schoolchildren. Optom Vis Sci

22 West SK, Muñoz B, Turner VM, et al. The epidemiology of trachoma in Central Tanzania. Int $\mathcal{f}$ Epidemiol 1991;20: 1088-92.

23 Schwab L, Whitfield R, Ross-Degnan D, et al. The epidemiology of trachoma in rural Kenya. Ophthalmology 1995;102 475-82.

24 Tielsch JM, West KP, Katz J, et al. The epidemiology of trachoma in southern Malawi. Am $\mathcal{f}$ Trop Med Hyg 1988;38:393-9.

25 West SK, Muñoz B, Lynch M, et al. Impact of face washing on trachoma in Kongwa, Tanzania. Lancet 1995;345:155-8.

26 Sommer A, West KP. Xerophthalmia and keratomalacia. In: Vitamin A deficiency: health, survival and vision. 1st ed. New York: Oxford University Press, 1996:99-149.

27 McLaren D. Towards the conquest of vitamin A deficiency disorders. 1st ed. Basle: Task Force Sight and Life, 1999:64-70.

28 Pratinidhi AK, Bapat VS, Shah U. Magnitude of vitamin A deficiency in primary school children of Sirar: a chronically deficiency in primary school children of Sirar: a chroni
drought affected area. Ind $\mathcal{F}$ Pediatr 1984;51:423-6.

29 Santos LMP, Dricot JM, Asciutti LS, et al. Xerophthalmia in Santos LMP, Dricot JM, Asciutti LS, et al. Xerophthalmia in
the state of Paraiba, northeast of Brazil: clinical findings. the state of Paraiba, northeast of
Am f Clin Nutr 1983;38:139-44.

30 Murugan S, Susheela TP, Belavady B. Plasma vitamin A and erythrocyte riboflavin in school children. Ind $\mathcal{F}$ Med Res 1977;65:533-42.

31 Kumar KA, Siddhu CMS, Chandra MR, et al. Serum vitamin A level of secondary school children. Ind $\mathcal{F}$ Pediatr 1976;368:368-77.

32 Congdon N, Sommer A, Severns M, et al. Pupillary and visual thresholds in young children as an index of population vitamin A status. Am f Clin Nutr 1995;61:1076-82.

33 Foster A, Gilbert CE. Epidemiology of visual impairment in children. In: Taylor D, ed. Paediatric Ophthalmology. 2nd ed. Oxford: Blackwell Science Ltd, 1997:3-12. 